\title{
DISCUSSION
}

\section{An approximate analysis of the three-dimensional effects of diaphragm wall installation}

\author{
C. W. W. NG, M. L. LINGS, B. SIMPSON and D. F. T. NASH (1995). Geotechnique 45 \\ No. 3, 497-507.
}

\section{W Powrie. University of Southampton}

In the vertical section analysis (VSA), the effects of wall installation are modelled by the application of a uniform horizontal displacement of the soil into the diaphragm wall trench. The fact that the displacement can be taken to be uniform with depth arises from the assumption that both the in situ lateral earth pressure coefficient $K_{0}$ (and hence the lateral stress reduction during wall installation) and the soil stiffness modulus increase in proportion to the depth below the soil surface.

In many overconsolidated clays, there is a trend of decreasing in situ earth pressure coefficient $K_{0}$ with depth. In these circumstances, the reductions in lateral stress during wall installation may be most significant close to the soil surface. Ignoring the possibility of a higher soil stiffness (resulting from the increased effective stresses due to negative pore water pressures) in the capillary saturated zone above the piezometric surface, the assumption that $K_{0}$ (and hence the lateral stress reduction during wall installation) decreases with depth could lead to an expectation that ground movements during wall installation might also decrease with depth below the soil surface. Have the authors investigated the effects of this or any other alternative patterns of imposed deformation on the results of the vertical section analysis?

It was noted by Powrie \& $\mathrm{Li}$ (1991) that the reduction of the lateral earth pressure coefficient in the soil above the toe of the wall to unity was not an ideal representation of the effects of diaphragm wall installation in that in reality, only the soil in the vicinity of the wall will be affected. The modelling of the effects of diaphragm wall installation as such, however, was not the main aim. The procedure was merely a device to obtain - without increasing the complexity of and the computational time required for the analysis - what was considered to be a less unrealistic starting point for an investigation of the post-installation behaviour of a diaphragm wall than the assumption that the wall had been installed without disturbing the in situ stress state. Having said this, it does seem that the imposition of an appropriate displacement profile (rather than a stress distribution) at the soil/wall interface to model the effects of diaphragm wall installation, along the lines proposed by the authors, could offer a less approximate approach. The pattern of the displacement profile that should be imposed, however, will probably be the subject of considerable debate.

\section{Author's reply}

Professor Powrie correctly notes that the effects of wall installation are modelled in the VSA by the application of a uniform horizontal displacement of the soil into the diaphragm wall trench. The justification for this is the assumption that the lateral stress reduction ( $K_{0}$ conditions to wet concrete pressures) and soil stiffness both increase in proportion to depth below the ground surface.

It is true that in many overconsolidated clays there is a trend of $K_{0}$ decreasing with depth. However, when there has been reloading, as at Lion Yard, the picture is more complex, and in these circumstances we believe the adoption of a constant $K_{0}$ value is reasonable. A full justification of this approach has been given by $\mathrm{Ng}$ (1992). We have not investigated the effects of alternative patterns of deformation on the results of the VSA.

An exception to this is in the region of the toe of the wall, where the horizontal displacement has been reduced to become zero at the toe. We have explored the sensitivity of the results to varying the height above the toe at which the displacement starts to reduce to zero. The height of $2 \mathrm{~m}$ used in the Paper was chosen as it gave a reasonable resulting stress profile without any large spikes.

In determining the reduction in lateral stress, both initial $K_{0}$ conditions and wet concrete pressures are equally important. As mentioned at the end of the discussion section in the Paper, wet concrete pressures do not increase uniformly with depth as assumed, but rather display a bilinear envelope with depth (Lings, Ng \& Nash, 1994). In practice, lateral stress reductions will depart from the simplifying assumptions of the approximate 
analysis, on account of factors affecting both initial and final stress conditions.

We accept the comments made in support of the approach taken to modelling wall installation by Powrie \& Li (1991). What the approximate analysis from the Paper has demonstrated is the importance of the mechanism of downward load transfer, whereby there is not only stress reduction in the vicinity of the wall, but also significant stress increase beneath the toe of the wall.

Debates on the pattern of displacement with depth are best informed by appropriate field measurements. The only such data relating to wall installation in stiff clay of which we are aware is that presented by Farmer \& Attewell (1973). They measured both vertical and horizontal soil displacements using instrumentation in four boreholes at various distances away from the centre-line of a diaphragm wall panel in London Clay. The layout of the panel and instrumentation is shown in Fig. 15. Profiles of horizontal deformation with depth are shown in Fig. 16, taken shortly after the panel had been concreted. No significant horizontal deformation was observed at borehole 4. Superimposed on Fig. 16 is the ground profile as revealed by borehole 1 .

Clearly the deformation measured $0.6 \mathrm{~m}$ from the trench wall is not uniform with depth. What is less clear is the explanation for this. Movement is concentrated near the top of the London Clay, which in the simple terms of the approximate analysis could be explained by a zone of weathered

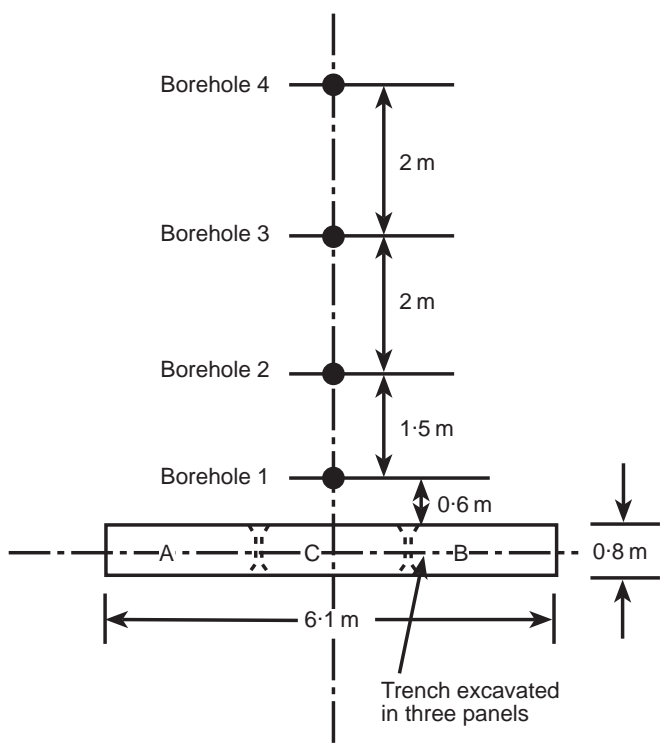

Fig. 15. Experimental layout (from Farmer \& Attewell, 1973)

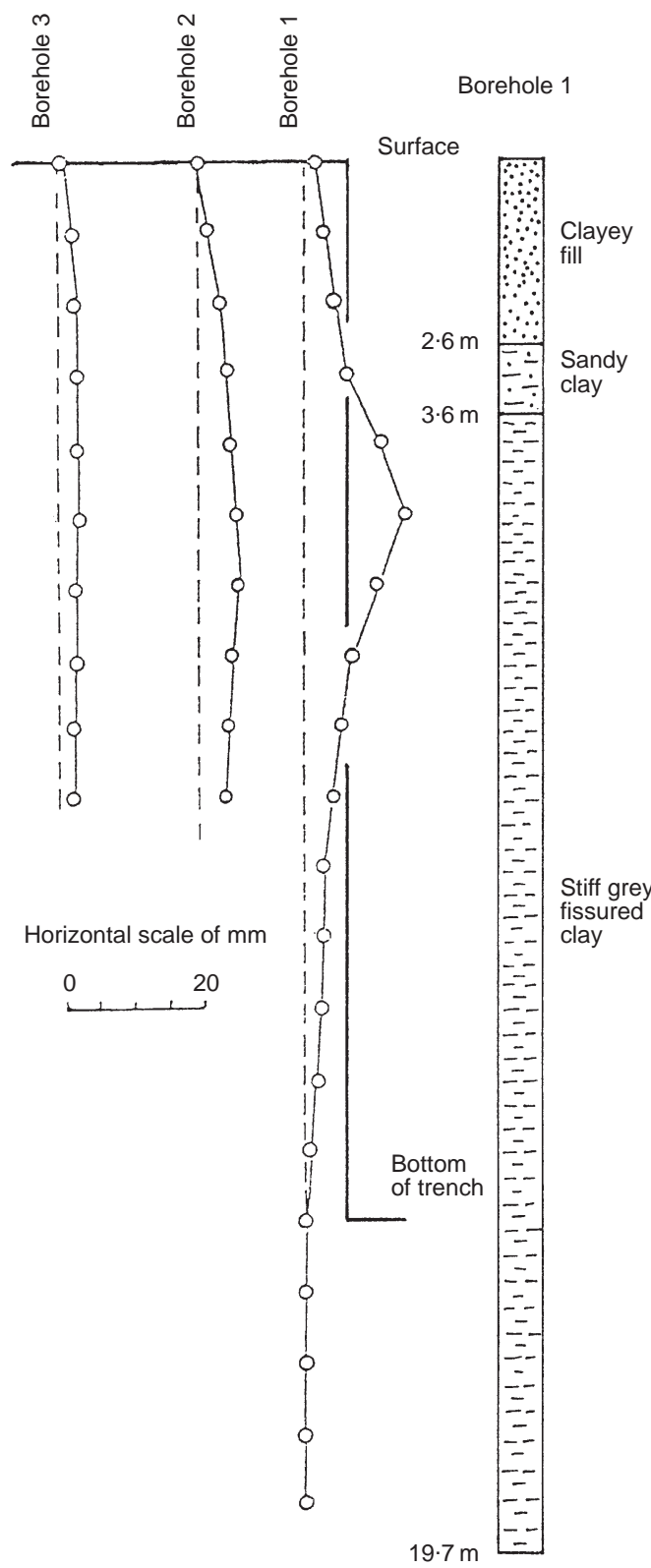

Fig. 16. Horizontal deformations and soil profile (after Farmer \& Attewell, 1973)

and less stiff material. In contrast, the deformation measured $4.1 \mathrm{~m}$ from the trench wall is surprisingly uniform with depth. Horizontal deformations at the ground surface are small, presumably due to the presence of a guide wall. The assumption made in the VSA of movement reducing to zero at the toe of the wall appears to be borne out in practice.

Some other points of interest emerge from a study of these data. The deformations shown in 
Fig. 16 were measured after the panel had been concreted, but the deformations that occurred after first completing the panel excavation under bentonite were surprisingly similar. As far as can be seen from the various data presented by Farmer \& Attewell (1973), the amount of deformation of the trench wall away from the wet concrete when placed was very small, of the order of $1 \mathrm{~mm}$. This implies very high soil stiffness on reversal of the direction of loading. In our approximate analysis, non-linear stiffness was accounted for in a very limited way be creating zones of different stiffness depending on proximity to the wall. To account for non-linearity arising from stress reversal, a proper non-linear soil model is required.

The panel was excavated in three stages (A, B $\& \mathrm{C}$ in Fig. 15), and significant deformation of the instrumented ground did not occur until excavation of stage C. This highlights the complexity of the construction process, and further points up the need for a full three-dimensional analysis.

\section{REFERENCES}

Farmer, I. W. \& Attewell, P. B. (1973). Ground movements caused by a bentonite-supported excavation in London Clay. Géotechnique 23, No. 4, 576-581.

Lings, M. L., Ng, C. W. W. \& Nash, D. F. T. (1994). The lateral pressure of wet concrete in diaphragm wall panels cast under bentonite. Proc. Instn Civ. Engrs Geotech. Engng, 107, July, 163-172.

Ng, C. W. W. (1992). An evaluation of soil-structure interaction associated with a multi-propped excavation. Ph.D. thesis, University of Bristol.

Powrie, W. \& Li, E. S. F. (1991). Finite element analyses of an in situ wall propped at formation level. Géotechnique 41, No. 4, 499-514. 